\title{
Correction to: Comparison of 2D vena contracta area with 3D planimetric mitral valve area in rheumatoid mitral valve disease
}

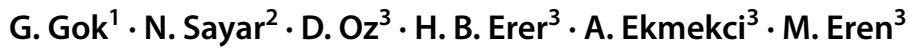

Published online: 22 October 2019

(c) Springer Nature B.V. 2019

\section{Correction to: The International Journal of Cardiovascular Imaging https://doi.org/10.1007/s10554-019-01673-y}

In the original publication of the article one co-author, A. Zencirci, was listed by mistake. Dr. A. Zencirci has not contributed to this article and therefore, the author list has been updated. The author name A. Zencirci has been removed. All authors have agreed to the updated author list.
Correct order given in this article.

The original article has been corrected.
Publisher's Note Springer Nature remains neutral with regard to jurisdictional claims in published maps and institutional affiliations.

The original article can be found online at https://doi.org/10.1007/ s10554-019-01673-y.

G. Gok

glygk84@gmail.com

1 Department of Cardiology, Medipol University Hospital, Istanbul, Turkey

2 Department of Cardiology, Marmara University Medical Center, Istanbul, Turkey

3 Department of Cardiology, Siyami Ersek Cardiovascular and Thoracic Surgery Center, Istanbul, Turkey 